\title{
Diagnosis of the Non-Concurrent Operation of the On-Load Tap Changer Contacts by the Acoustic Emission Method
}

\author{
Andrzej CICHOŃ, Sebastian BORUCKI, Tomasz BOCZAR \\ Technical University of Opole \\ Institute of Electric Power Engineering \\ Prószkowska 76, building 2, 45-758 Opole, Poland \\ e-mail: \{a.cichon, s.borucki, t.boczar\}@po.opole.pl \\ (received November 29, 2011; accepted July 29, 2011)
}

\begin{abstract}
On-load tap changers (OLTC) are some of the main transformer elements that make voltage adjustment in a power network possible. Their failures often cause shutdowns of distribution transformers. The paper presents research work aimed at the assessment of the technical condition of OLTCs by the acoustic emission method (EA). This method makes the OLTC diagnosis possible without the need of disconnecting the transformer from the system. The measurements were taken in laboratory conditions. The influence on the operation non-concurrence of the power tap changer contacts on the AE registered signals has been investigated. The signals registered were subjected to analyses in the time and time-frequency domains. The result analysis in the time domain was carried out using the Hilbert transform and calculating characteristic times for the particular runs. A short-time Fourier transform was used for the assessment of results in the time-frequency domain.
\end{abstract}

Keywords: power transformer, on-load tap changers, acoustic emission method.

\section{Introduction}

The application of the acoustic emission method for the diagnosis of power transformers makes it possible to assess the technical condition of these appliances during their regular live operation, which is, undoubtedly, its advantage (Boczar et al., 2009; Cichoń, 2009; Kundu et al., 2008; Skubis et al., 2009). The essential application of this method is the possibility of detection of partial discharges occurring in the internal insulation system of the appliance. The analysis of the transformer failure rate showed that ca. $20 \%$ of all transformer failures 
is caused by defective work of the on-load tap changers (OLTC), which constitute vital elements of transformers (Energo-Complex, Transformers in exploitation, 2007; Report of the Polish Society of the Transmission and Distribution of the Electricity, 2002). Mating with voltage regulators in a network, these appliances enable voltage elevation and reduction by performing changeovers between the particular tips of the regulating windings. Presently, the assessment of the OLTC technical condition is carried out most often by the oscillographic method. The measurements may be taken only off-line disconnecting the unit under study from voltage (ERBRINK et al., 2008).

A constantly increasing demand for electric energy, maintenance works and limited changeover possibilities resulting from the network structure cause that in the operation practice the problems connected with the necessity of transformer shut-downs for routine diagnostic investigations are more and more frequent. The relatively high OLTC failure coefficient has become the reason for looking for new diagnostic methods, which would make it possible to assess their technical condition on-line. The OLTC connection process is related to the generation of acoustic signals, which makes the application of the AE method for diagnosis of their technical condition possible (FIlHo, DE Almeida, 2008; Rivas et al., 2009). One of the main causes of OLTC failures is the changeover nonconcurrence of the power changer contacts in all three phases. This phenomenon leads to an excessive wear of the contacts, which are exposed to an electric arc and voltage interference in the network. The paper presents research work results on detection of non-concurrence of the power changer contacts by the $\mathrm{AE}$ method.

\section{Characteristics of the measuring system}

The investigations were carried out in laboratory conditions. The main element of the test stand was a specially constructed measuring tank of the dimensions $50 \times 60 \times 80 \mathrm{~cm}$, enabling to insert the power changer under study inside it. The changer was attached to the tank bottom in such a way as to be immobilized during changeovers. The container was filled with insulation oil to make the laboratory measurement conditions as close to real conditions during a changer operation as possible. The view of the power changer is shown in Fig. 1.

The measurements of the acoustic signals were taken with a wide-band measuring transducer of type WD AH 17 by PAC, which was attached to the external part of the tank with a magnetic holder. The acoustic signal registered with the transducer was subjected to amplification in the preamplifier system of type $2 / 4 / 6$ preamplifier by PAC. The measurement signal from the preamplifier was connected to the amplifying system subjecting the acoustic signal to amplification of $20 \mathrm{~dB}$. An overall view of the measuring apparatus is shown in Fig. 2. 


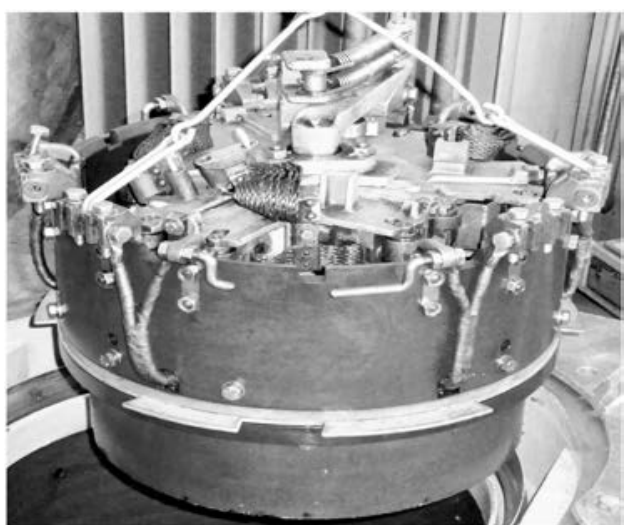

Fig. 1. A view of the power changer under study.

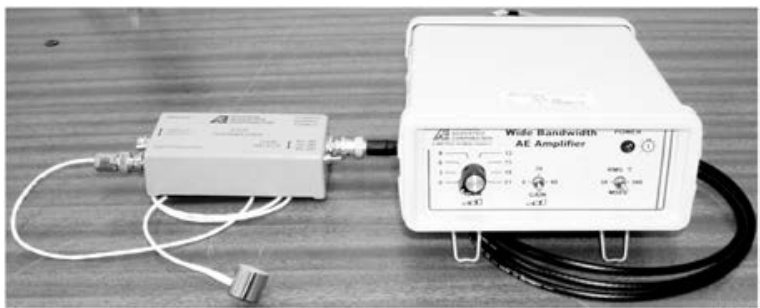

Fig. 2. A view of the measuring apparatus.

\section{Methodology of taking measurements}

During the investigations, the thickness of the power changer even main contacts remained unchanged, while the thickness of the odd contacts was changed by applying specialized pads, which matched the size and shape of the contacts. In particular phases, the thickness was differentiated in the following way:

- phase A - contact thickness was unchanged,

- phase B - contact thickness was increased by $3 \mathrm{~mm}$,

- phase $\mathrm{C}$ - contact thickness was increased by $6 \mathrm{~mm}$.

The measurements were taken for two work directions of the power changer: from even contacts to odd ones and in the opposite direction. Due to the differences occurring in the acoustic signals, the result analysis was presented for both work directions of the power changer. The measurement result assessment was carried out in the time and in the time-frequency domains.

The research results in the time domain are shown in the form of runs determined for the whole signal registered and for the signals shortened to $100 \mathrm{~ms}$ in the form of Hilbert transform modules. In the recorded AE signals three structures characterized by a large maximal value can be distinguished. On their basis three characteristic times that characterize the typical distance between these structures have been designated: 
- T1, between the first and second structures,

- $\mathrm{T} 2$, between the second and third structures,

- Tc, between the first and third structures.

The characteristic times have been determined from the time runs as presented in Fig. 3.

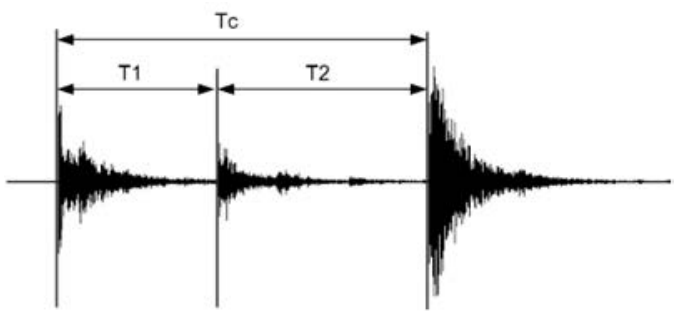

Fig. 3. The way of determining characteristic times of the acoustic signals generated by OLTC.

The assessment of the acoustic signals registered in the time-frequency domain was carried out using a short-time Fourier transform presenting two-dimensional spectrograms of the power spectral density.

\section{Analysis of the measurement results}

Figure 4 shows time runs of the acoustic signals registered during the work of the power changer in both directions.

a)
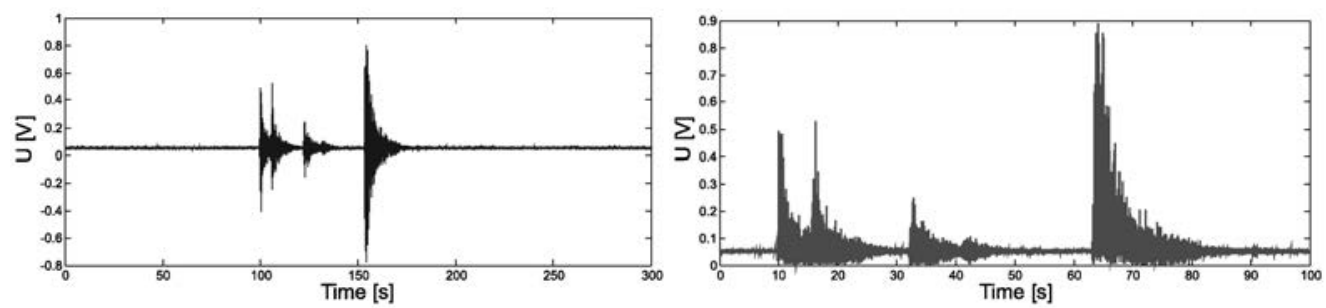

b)
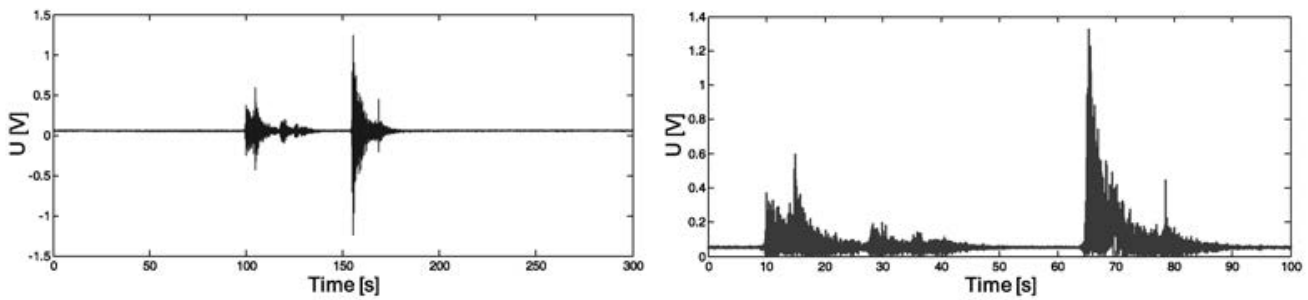

Fig. 4. Time runs and Hilbert transform modules of the acoustic signals of the power changer with modeled change-over non-concurrence at work: a) in the direction from odd to even contacts, b) in the direction from even to odd contacts. 
Analyzing the time runs of the acoustic signals, which correspond to both work directions of the power changer with a modeled work non-concurrence, the following differences between them may be observed. They refer, first of all, to Structure Two (S2) occurring after time T1. The other parts of the signals analyzed are characteristic of a great similarity, both in respect of shape and acoustic events, and the occurring differences refer only to the amplitude values. For the acoustic signal generated at the transfer from odd to even contacts, i.e. the contacts of an equal thickness, structure S2 is characteristic of a significant coherence and a shorter duration time. Two characteristic acoustic events may be distinguished in it: the first one of a bigger and the other one of a smaller amplitude value. During the changeover in the opposite direction - on various thickness contacts, the structure is characteristic of a bigger number of acoustic events of small amplitude. In this case structure S2 is also characteristic of a lower coherence and a longer duration time.

In order to depict measurably the differences in the runs analyzed, characteristic times were determined, which are shown in Table 1 and in Fig. 5.

Table 1. Listing of characteristic times of the power changer acoustic signals with a modeled non-concurrence of work.

\begin{tabular}{|c|c|c|c|}
\hline Power changer work direction & $\mathrm{T} 1[\mathrm{~ms}]$ & $\mathrm{T} 2[\mathrm{~ms}]$ & $\mathrm{Tc}[\mathrm{ms}]$ \\
\hline from odd to even contacts & 22.5 & 31.0 & 53.5 \\
\hline from even to odd contacts & 19.4 & 34.4 & 53.8 \\
\hline
\end{tabular}

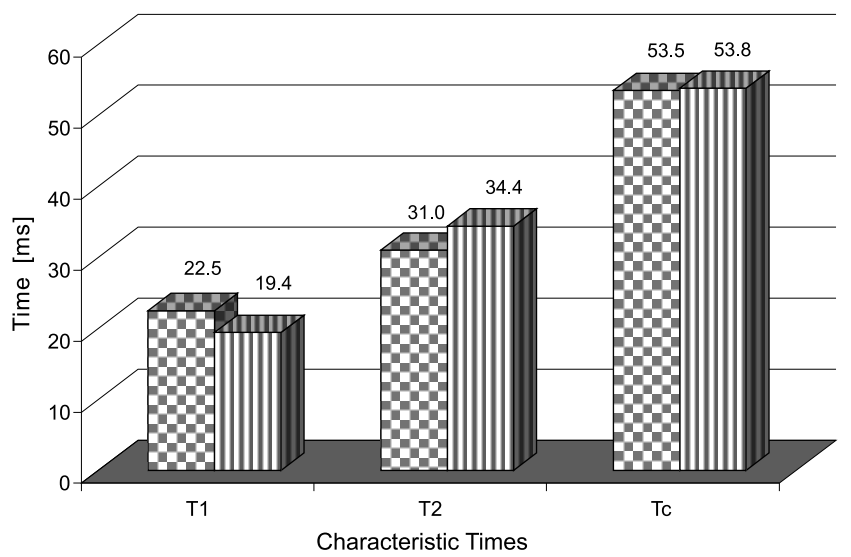

Fig. 5. Characteristic times of the power changer acoustic signals at work with a modeled work non-concurrence.

The differences between the total times Tc determined for both change-over directions are $0.3 \mathrm{~s}$. Hence it can be assumed that they are insignificant for the assessment of the work non-concurrence degree of the power changer. However, times T1 and T2 undergo significant changes. During a changeover from even 
to odd contacts, shortening of time $\mathrm{T} 1$ and extension of time $\mathrm{T} 2$ occur. The differences between the times analyzed for changeovers in both directions are: $3.1 \mathrm{~ms}$ for time $\mathrm{T} 1$ and 3.4 for time $\mathrm{T} 2$, respectively.

Additionally, the assessment of the acoustic signals in the time domain was supplemented with the analysis carried out in the time-frequency domain determining the spectrograms of the power spectral density shown in Fig. 6.

a)

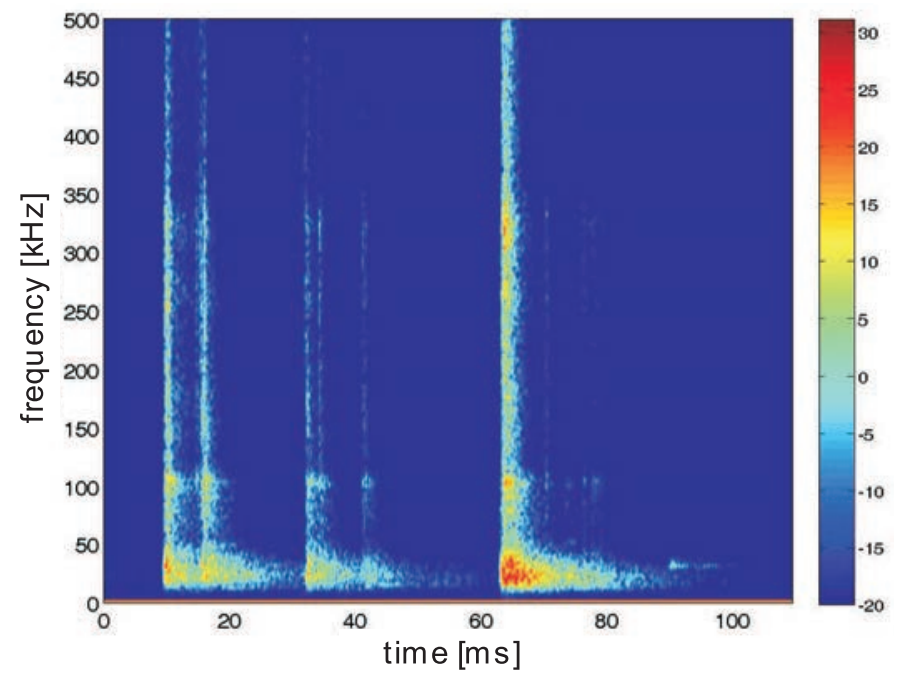

b)

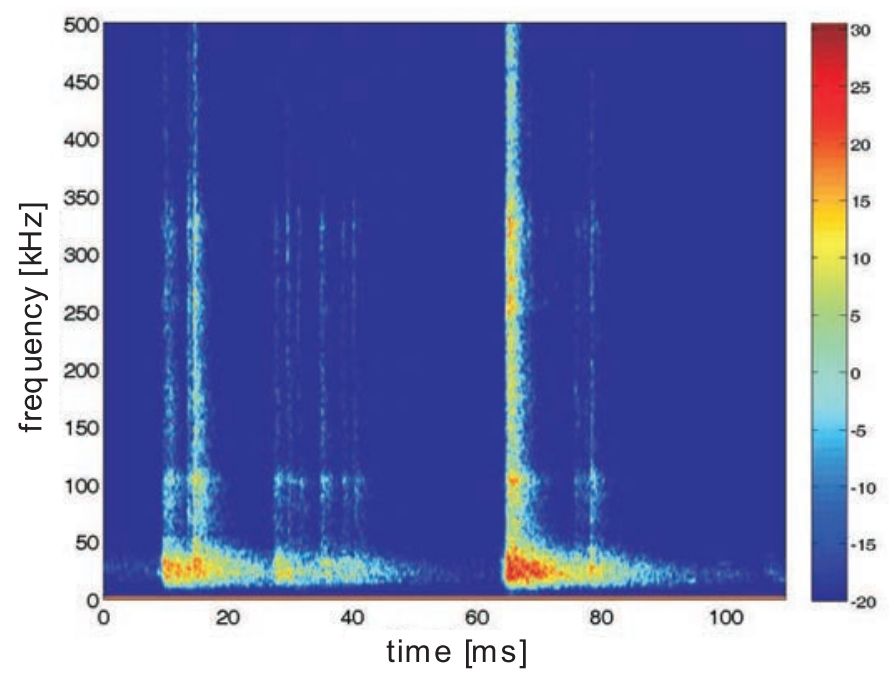

Fig. 6. Power spectral density spectrograms of the acoustic signals with a modeled work nonconcurrence of the power changer in the directions: a) from odd to even contacts, b) from even to odd contacts. 
On both spectrograms shown above, the participation of lower frequencies occurring in the band up to $60 \mathrm{kHz}$ is dominant. Like during the analysis of the time runs, the biggest differences between the signals under study refer to structure S2. These structures occur on both spectrograms and are characteristic of a similar participation of time-frequency components. The characteristic features of the structure corresponding to the power changer work in the direction from even to odd contacts (contacts of various thickness) are a bigger number of components from the band above $60 \mathrm{kHz}$, clear delamination of the structure and its longer duration time.

\section{Summing-up}

The measurement results presented confirm the application possibility of the acoustic emission method for detecting work non-concurrence of a power changer. It is necessary to conduct further research to confirm the results obtained on the objects being in use. The measurement results may provide a basis for creating a diagnostic system of OLTC monitoring their condition on-line.

\section{Acknowledgment}

The work was financed with the means from the National Research and Development Center within LIDER program.

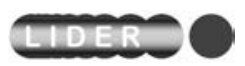

\section{References}

1. Boczar T., Borucki S., Cichoń A., ZmarzŁy D. (2009), Application Possibilities of Artificial Neural Networks for Recognizing Partial Discharges Measured by the Acoustic Emission Method, IEEE Transactions on Dielectrics and Electrical Insulation, 16, 1, 214-223.

2. Cichoń A. (2009), The Application of the Selected Time-Frequency Descriptors Detection of the Acoustic Emission Signals Generated by Multisource Partial Discharges, Acta Physica Polonica A, 116, 3, 290-293.

3. Energo-Complex (2007), Transformers in exploitation [in Polish: Transformatory w eksploatacji], 2nd Ed., collective work under J. Subocz [Ed.], Piekary Śląskie.

4. Erbrink J.J., Gulski E., Seitz P.P., Leich R. (2008), Advanced on-site diagnosis of transformer on-load tap changer, Proceedings of the International Symposium on Electrical Insulation, pp. 252-256.

5. Filho E.F.S., De Almeida L.A.L. (2008), Self-Organized Classification of on-load tap Changers acoustic signature, Proceedings of the International Instrumentation and Measurement Technology Conference, Victoria, pp. 1051-1056. 
6. Kundu P., Kishore N.K., Sinha A.K. (2008), Behavior of Acoustic Partial Discharge Signal in Oil-Pressboard Insulation System, Proceedings of the International Conference Industrial and Information Systems, Kharagpur, pp. 1-6.

7. Report of Polish Society of the Transmission and Distribution of the Electricity (2002), Analysis of failure of transformer $M V / L V$ on the example of some of the distribution companies [in Polish: Analiza awaryjności stacji transformatorowych $S N / n N$ na przykładzie wybranych spótek dystrybucyjnych], Poznań.

8. Rivas E., Burgos J.C., García-Prada J.C. (2009), Condition Assessment of Power OLTC by Vibration Analysis Using Wavelet Transform, IEEE Transactions on Power Delivery, 24, 2, 687-694.

9. Skubis J., Cichó́ A., Borucki S. (2009), Practical example of effective detection and location of partial discharges in power transformer using acoustic emission method [in Polish: Praktyczny przyktad skutecznej detekcji i lokalizacji wyladowań niezupetnych metoda emisji akustycznej w transformatorze elektroenergetycznym], Pomiary Automatyka Kontrola, 55, $1,30-33$. 